Gut and Liver, Vol. 10, No. 5, September 2016, pp. 851-858

\title{
MUC Expression in Gallbladder Epithelial Tissues in Cholesterol-Associated Gallbladder Disease
}

Kyo-Sang Yoo ${ }^{1}$, Ho Soon $\mathrm{Choi}^{1}$, Dae Won Jun ${ }^{1}$, Hang Lak Lee ${ }^{1}$, Oh Young Lee ${ }^{1}$, Byung Chul Yoon ${ }^{1}$, Kyeong Geun Lee ${ }^{2}$, Seung Sam Paik ${ }^{3}$, Yong Seok Kim ${ }^{4}$, and Jin Lee ${ }^{5}$

Departments of ${ }^{1}$ Internal Medicine, ${ }^{2}$ General Surgery, ${ }^{3}$ Pathology, and ${ }^{4}$ Biochemistry and Molecular Biology, Hanyang University College of Medicine, Seoul, and ${ }^{5}$ Department of Internal Medicine, Hallym University College of Medicine, Hwaseong, Korea

Background/Aims: Gallstone pathogenesis is linked to mucin hypersecretion and bacterial infection. Several mucin genes have been identified in gallbladder epithelial cells (GBECs). We investigated MUC expression in cholesterolassociated gallbladder disease and evaluated the relationship between mucin and bacterial infection. Methods: The present study involved 20 patients with cholesterol stones with cholecystitis, five with cholesterol stones with cholesterolosis, six with cholesterol polyps, two with gallbladder cancer, and six controls. Canine GBECs treated with lipopolysaccharide were also studied. MUC3, MUC5AC, MUC5B, and MUC6 antibodies were used for dot/slot immunoblotting and immunohistochemical studies of the gallbladder epithelial tissues, canine GBECs, and bile. Reverse-transcription polymerase chain reaction was performed to evaluate MUC3 and MUC5B expression. Results: MUC3, MUC5AC, MUC5B, and MUC6 were expressed in the normal gallbladder epithelium, and of those, MUC3 and MUC5B exhibited the highest expression levels. Greatly increased levels of MUC3 and MUC5B expression were observed in the cholesterol stone group, and slightly increased levels were observed in the cholesterol polyp group; MUC3 and MUC5B mRNA was also upregulated in those groups. Canine GBECs treated with lipopolysaccharide also showed upregulation of MUC3 and MUC5B. Conclusions: The mucin genes with the highest expression levels in gallbladder tissue in cholesterol-associated diseases were MUC3 and MUC5B. Cholesterol stones and gallbladder infections were associated with increased MUC3 and MUC5B expression. (Gut Liver 2016;10:851-858)

Key Words: MUC3; MUC5B; Gallstones; Cholesterol; Infection

\section{INTRODUCTION}

Gallbladder mucin (MUC) genes are thought to be involved in the pathogenesis of cholesterol associated gallbladder disease. ${ }^{1}$ However, the role of MUC genes in gallstone formation is unclear. Of all gallstones, 80\% are cholesterol gallstones, the formation of which is related to cholesterol supersaturation, nucleation of cholesterol crystals, and gallbladder hypomotility. Some studies have suggested that MUC genes are a contributing factor in cholesterol crystal nucleation., ${ }^{2,3}$ Other studies support a possible relationship between MUC and pigment stones, which are closely related to infection. ${ }^{4-6}$

Lipopolysaccharide (LPS) is a metabolic product of Escherichia coli thought to be involved in MUC expression in biliary cells. E. coli DNA was found in all brown pigment and mixed cholesterol gallstones. ${ }^{7}$ These findings suggest that bacterial infection stimulates mucin secretion from gallbladder epithelial cells, ${ }^{8,9}$ contributing to formation of pigment stones. Bacterial infection, bile stasis, mucin hypersecretion, and changes in mucin characteristics such as gel-forming apomucin of the biliary tract contribute to gallstone formation. ${ }^{10}$ However, only a few studies have investigated MUC expression in cholesterol-associated gallbladder disease. Published reports differ on the MUC genes related to lithogenic mucin., ${ }^{1,5,11,12}$

To date, more than 20 MUC genes have been identified. ${ }^{13}$ These genes demonstrate cell-specific expression and distribution in humans. ${ }^{14-22}$ Although reports vary slightly, it is generally agreed that at least nine MUC genes (MUC1, MUC2, MUC3A, MUC3B, MUC4, MUC5AC, MUC5B, MUC6 and MUPCDH) are expressed in gallbladder and/or its associated diseases. ${ }^{23-29}$ There is still some disagreement about which is the principle gallbladder MUC.

Correspondence to: Ho Soon Choi

Department of Internal Medicine, Hanyang University College of Medicine, 220 Wangsimni-ro, Seongdong-gu, Seoul 04763, Korea

Tel: +82-2-2290-8379, Fax: +82-2-2298-9183, E-mail: hschoi96@hanyang.ac.kr

Received on November 26, 2015. Revised on February 12, 2016. Accepted on April 13, 2016.

pISSN 1976-2283 eISSN 2005-1212 http://dx.doi.org/10.5009/gnl15600

(a) This is an Open Access article distributed under the terms of the Creative Commons Attribution Non-Commercial License (http://creativecommons.org/licenses/by-nc/4.0) which permits unrestricted non-commercial use, distribution, and reproduction in any medium, provided the original work is properly cited. 
A recent study demonstrated that several mucin proteins were overexpressed in the gallbladder especially with pigment stones and inflamed gallbladder. ${ }^{30}$ However, expression of various MUC in gallbladder with cholesterol gallstone and cholesterol stone-related disease still remains largely unknown. Aim of present study was to investigate mucin expression in normal human gallbladder epithelium and in gallbladder epithelial tissue from patients with cholesterol gallstone diseases and also to investigate the relationships between bacterial infection and MUC genes.

\section{MATERIALS AND METHODS}

\section{Study population}

This study included 20 patients with histologically proven postoperative cholesterol stones with accompanying cholecystitis, five with cholesterol stone with cholesterolosis, six with cholesterol polyps, two with gallbladder cancer, and six normal controls. In vitro studies were performed using cultured dog gallbladder epithelial cells (DGBECs). Human bile was removed by surgical aspiration with a syringe. Bile was obtained after cleaning the gallbladder's inner surface with phosphate buffered solution and was filtered before use.

Human gallbladders removed in elective surgeries for clinically-indicated reasons were used for this study. To identify cholesterol stones, the external appearance and cut surface of the removed gallstones were inspected. Cholesterol stones are pale yellow with a mulberry-like appearance, and, upon sectioning, a crystalline radial pattern can be seen. The presence of these characteristics was considered sufficient for diagnosis of pure cholesterol stones.

\section{Experimental drugs and materials}

Vitrogen (Celtrix Laboratories, Palo Alto, CA, USA) and plastic tissue culture containers (Falcon, Lincoln Park, NJ, USA) were used. Transwell cell culture containers were 24-mm in diameter with 3.0- $\mu \mathrm{m}$ pore size (Costar, Cambridge, MA, USA). Media and cell culture solutions including Eagle's medium essential medium (EMEM), fetal bovine serum, trypsin ethylenediaminetetraacetic acid (EDTA), and penicillin-streptomycin were from Sigma (St. Louis, MO, USA).

\section{Cell culture}

DGBECs were obtained as previously described. ${ }^{27}$ To obtain a stable cell line, $2 \mathrm{~mL}$ Vitrogen gel (1:1 Vitrogen: medium) was added to petri dishes containing trypsin-digested tissue, followed by $10 \mathrm{~mL}$ EMEM with $2 \mathrm{mM}$ L-glutamine, $20 \mathrm{mM}$ HEPES, $100 \mathrm{IU} / \mathrm{mL}$ penicillin, and $100 \mathrm{mg} / \mathrm{mL}$ streptomycin. The dishes were then incubated under $5 \% \mathrm{CO}_{2}$ at $37^{\circ} \mathrm{C}$. Culture medium was changed twice weekly until the cells were mature, after which they were subcultured after treatment with trypsin $(2.5 \mathrm{~g} / \mathrm{L})$ and EDTA ( $1 \mathrm{~g} / \mathrm{L})$. A single cell line was used after 2 to
10 subcultures.

\section{Management of LPS in DGBECs}

DGBECs were treated with 100 or $200 \mu \mathrm{g} / \mathrm{mL}$ LPS (L2630; Sigma) after culturing for 6 days. According to the categorized groups, protein was extracted after 4, 8, or 24 hours of LPS treatment for 10 minutes in room temperature stripping solution (Pierce, Rockford, IL, USA).

\section{Immunohistochemical staining of MUC3, MUC5AC, MUC5B, and MUC6 proteins in gallbladder epithelium}

Paraffin tissue blocks were sliced into $4-\mu \mathrm{m}$ sections and cleaned in running water after deparaffinization and hydration. After 10 minutes of blocking, 1:20 goat antihuman MUC3, MUC5AC, MUC5B, and MUC6 polyclonal antibodies (Santa Cruz Inc., Santa Cruz, CA, USA) were added for 1 hour. Biotinylated rabbit anti-goat IgG (DAKO, Carpinteria, CA, USA) was added for 20 minutes at room temperature. Streptavidin-biotin complex (DAKO) was added for 20 minutes, and 3,3-diaminobenzidine tetrahydrochloride (DAB) was used as a coloring agent. Goat serum was used as the negative control. Microscopic examination was performed after counterstaining with Mayer's hematoxylin. Immunohistochemical staining was classified as positive or negative based on presence.

Immunohistochemical results were independently evaluated by two investigators (H.S.C. and S.S.P.). The results were evaluated for both percentage and intensity of stained cells. Staining intensity was graded as negative, weak, moderate or strong. When $<10 \%$ of positive cells stained and/or the intensity was 0 or 1 , immunostaining was considered to be negative.

\section{Dot/slot blotting and immunodetection}

Quantitation of mucin in bile, human gallbladder tissue, and DGBECs was accomplished by blotting onto nitrocellulose membranes with a Minifold II dot/slot blot apparatus (Schleicher \& Schuell Inc., Keene, NH, USA). Membranes were air dried, blocked for 2 hours in 5\% skim milk in Tween/Tris-buffered saline (TTBS), and washed three times with TTBS. Goat antihuman polyclonal antibodies for MUC3, MUC5AC, MUC5B, and MUC6 (Santa Cruz Inc.) were added at $4^{\circ} \mathrm{C}$ for at least 12 hours before washing three times with TTBS. All other samples were mixed with anti-goat IgG (Pierce) for 1 hour at room temperature. The ECL Plus Western blotting detection system (Amersham Pharmacia, Freiburg, Germany) was utilized for detection.

\section{Reverse-transcription polymerase chain reaction}

Reverse-transcription polymerase chain reaction (RT-PCR) was used to determine expression of MUC3 and MUC5B genes in gallbladder tissue and DGBECs. The primers used were as follows: MUC3 forward, 5'-TGT CAG CTC CAG ACC AGA TG-3'; reverse, 5'-CCT GCT CAT ACT CGC TCT CC-3'; MUC5B forward, 5'-ATG AAA CCT GGG TCA ACA GC-3'; reverse, 5'-ATC CAC 
GTG GGT GTA GGT GT-3'. Primers $(10 \mathrm{mM})$ were combined with $0.1 \mu \mathrm{g} / \mathrm{mL}$ total RNA, $5 \mathrm{mM} \mathrm{MgCl}_{2}, 10 \mathrm{mM}$ dNTPs, $2.5 \mathrm{U}$ Taq polymerase (Promega, Medison, WI, USA), and $\mathrm{ddH}_{2} \mathrm{O}$ at reaction volumes of $50 \mu \mathrm{L}$. Amplification was performed with a GeneAmp PCR system 9600 (Perkin Elmer, Norwalk, CT, USA) in the following steps: 5 minutes of denaturation at $94^{\circ} \mathrm{C} ; 35$ cycles of 30 seconds at $94^{\circ} \mathrm{C}, 30$ seconds at $60^{\circ} \mathrm{C}$, and 2 minutes at $75^{\circ} \mathrm{C}$; and final extension for 5 minutes at $72^{\circ} \mathrm{C}$. PCR products were visualized on $2 \%$ agarose gels stained with ethidium bromide $(0.5 \mu \mathrm{g} / \mathrm{mL})$. Final analysis was conducted with the Quantity One program of a Fluor- $S^{\mathrm{TM}}$ Multi-Imager (Bio-Rad, Hercules, CA, USA).

\section{Statistical analysis}

ANOVA was performed for data sets containing at least three groups, and Student t-tests were used for comparisons between two data groups. Statistical significance was established at $\mathrm{p}<0.05$.

\section{RESULTS}

\section{MUC expression in normal gallbladder epithelium}

Immunohistochemical staining with specific antibodies was positive for MUC3, MUC5AC, MUC5B, and MUC6 proteins in normal gallbladder epithelium. With MUC3 and MUC5B having the highest expression, and MUC5B being the most prominent (Fig. 1).

\section{MUC expression in gallbladders with cholesterol stones}

Immunohistochemical staining was performed on gallbladder epithelium from patients with cholesterol stones and either cholesterolosis or cholecystitis and compared to normal gallbladder epithelium. MUC3 and MUC5B were significantly overexpressed in the cholesterol stone group compared with the normal control group (Fig. 2). The presence of cholecystitis or cholesterolosis did not affect expression of MUC3 or MUC5B in the cholesterol stone group. MUC5AC was also overexpressed in the cholesterol stone group, although it was weak. No difference in MUC5AC or MUC6 expression was observed between any of these groups.

\section{MUC expression in gallbladders with cholesterol polyps}

MUC3 and MUC5B were overexpressed in the gallbladder epithelium of patients with cholesterol polyps compared to normal controls. Expression of MUC3 and MUC5B was similar between patients with cholesterol polyps and those with gallbladder cancer. Expression of MUC5AC was weakly increased in both cholesterol polyp and gallbladder cancer group. However, no significant differences were seen in the expression of MUC5AC or MUC6 among the cholesterol polyp, gallbladder cancer, or normal control groups (Fig. 3). Expression of MUC in the gallbladder epithelium is summarized in Table 1. The most prominent overexpression of MUC3 and MUC5B was seen in gallbladder epithelium samples from patients with cholesterol stones.

\section{Expression of MUC in bile, gallbladders with cholesterol stones and cholecystitis, and DGBECs with inflammation}

Immunodetection by dot/slot blotting was used to compare inflamed gallbladder tissue, infected bile, and LPS-treated DGBECs with normal controls. Overexpression of MUC3, MUC5AC, MUC5B, and MUC6 was noted in the bile of patients with cho-
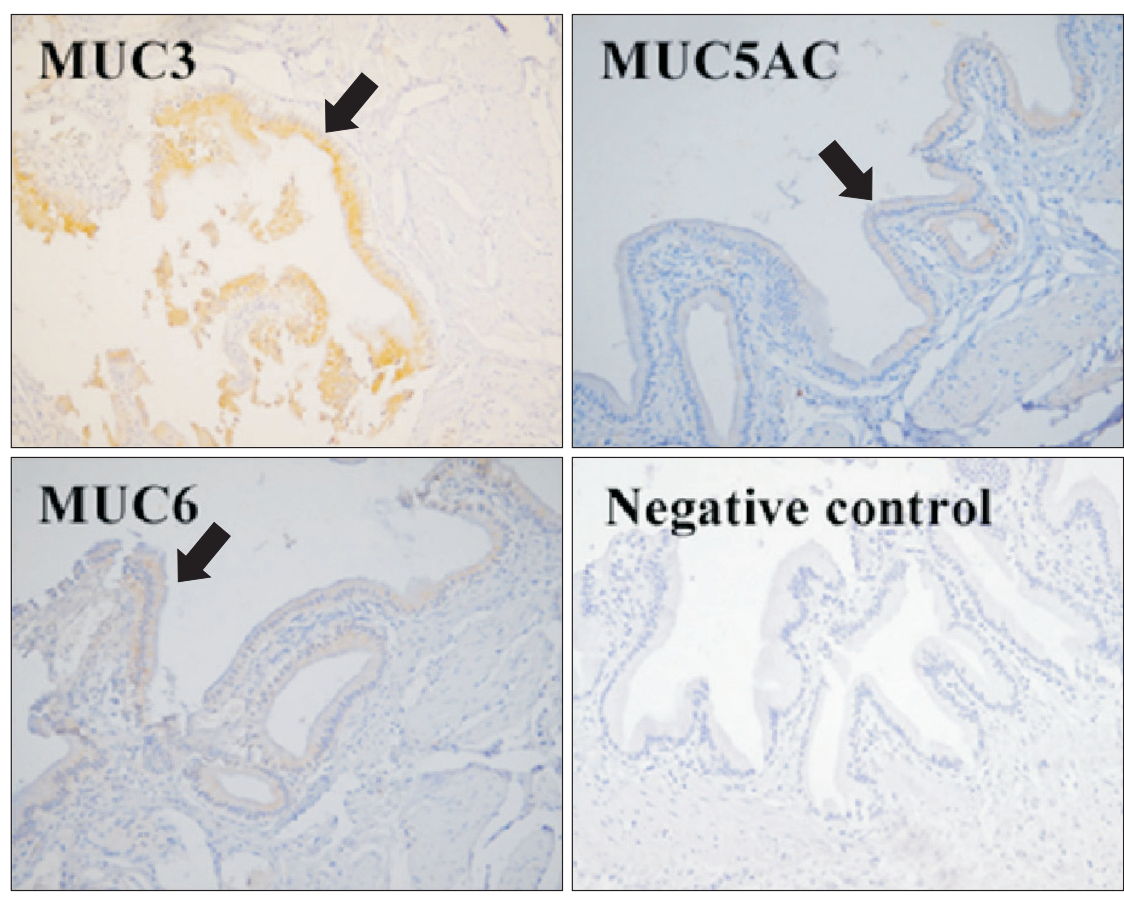

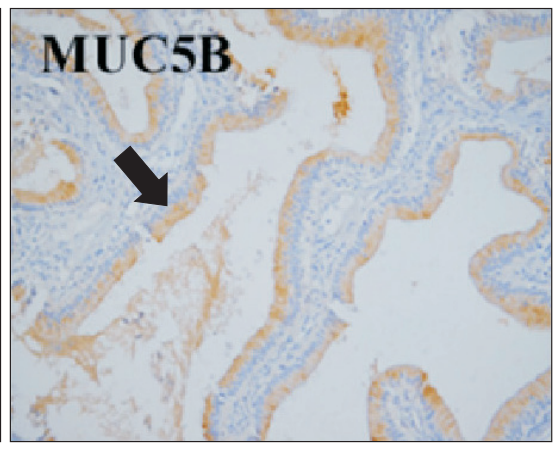

\section{Negative control}

Fig. 1. Immunohistochemistry $(\times 200)$ of a healthy gallbladder. MUC3, MUC5AC, MUC5B, and MUC6 were expressed in the superficial epithelium and folds (arrows). MUC3 and MUC5B were the most prominently expressed proteins. 

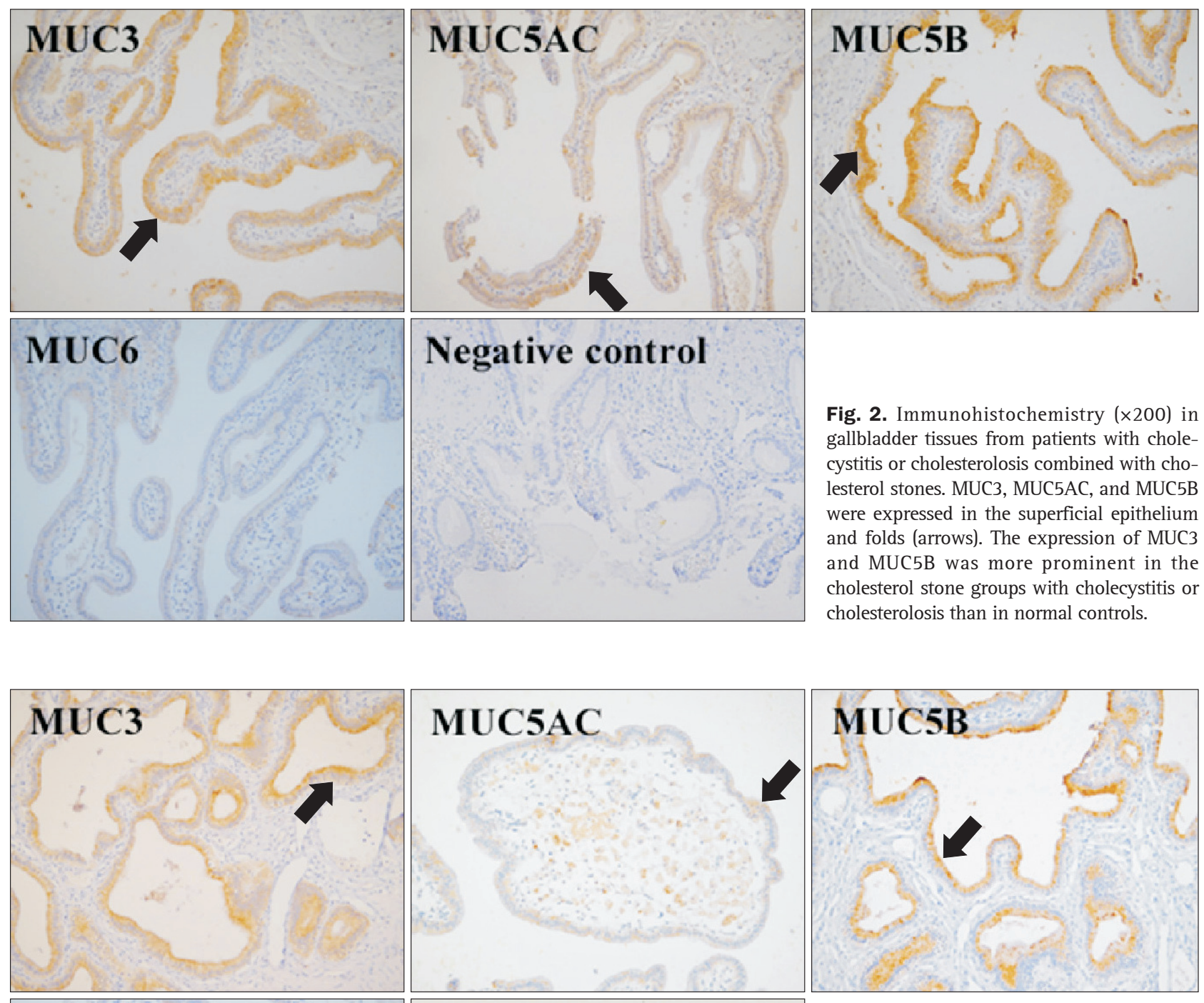

Fig. 2. Immunohistochemistry $(\times 200)$ in gallbladder tissues from patients with cholecystitis or cholesterolosis combined with cholesterol stones. MUC3, MUC5AC, and MUC5B were expressed in the superficial epithelium and folds (arrows). The expression of MUC3 and MUC5B was more prominent in the cholesterol stone groups with cholecystitis or cholesterolosis than in normal controls.

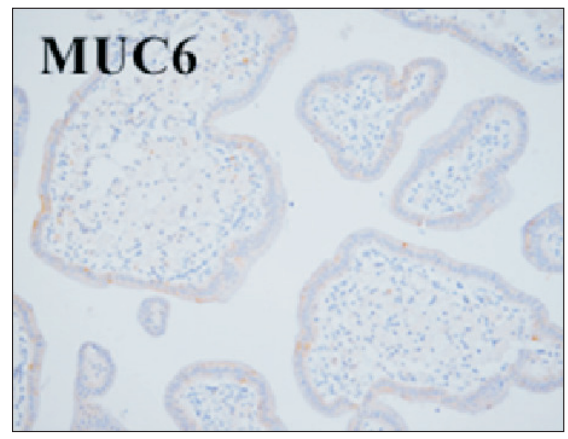

\section{Negative control}

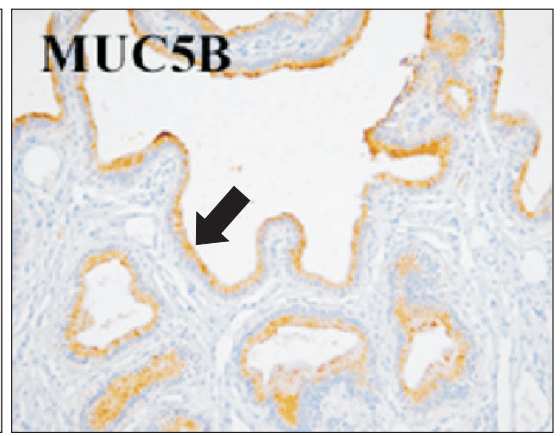

Fig. 3. Immunohistochemistry $(\times 200)$ in cholesterol polyp tissue. MUC3, MUC5AC, and MUC5B were expressed in the superficial epithelium and folds (arrows). MUC3 and MUC5B expression levels were slightly increased in the cholesterol polyp group compared to the normal controls.

Table 1. Mucin Expression in Gallbladder Tissue as Shown by Immunohistochemistry

\begin{tabular}{|c|c|c|c|c|c|}
\hline \multirow{2}{*}{ Histopathology } & \multirow{2}{*}{ Cases } & \multicolumn{4}{|c|}{ Tissue } \\
\hline & & MUC3 & MUC5AC & MUC5B & MUC6 \\
\hline Normal & 6 & + & \pm & ++ & \pm \\
\hline Cholecystitis with $\mathrm{CHO}$ stone & 20 & ++ & \pm & +++ & \pm \\
\hline Cholesterolosis with $\mathrm{CHO}$ stone & 5 & ++ & \pm & +++ & \pm \\
\hline Cholesterol polyp & 6 & ++ & \pm & ++ & \pm \\
\hline GB cancer & 2 & + & \pm & ++ & \pm \\
\hline
\end{tabular}

CHO, cholesterol; GB, gallbladder; \pm , weak; +, moderate; ++ or +++, strong. 
lecystitis compared to controls, with significant increases in MUC3 and MUC5B. Expression of MUC3, MUC5B, and MUC6 in DGBECs treated with LPS was slightly higher than that in untreated DGBECs. Expression of MUC3 and MUC5B increased in bile, gallbladder tissue and DGBECs compared to that in the controls (Fig. 4).

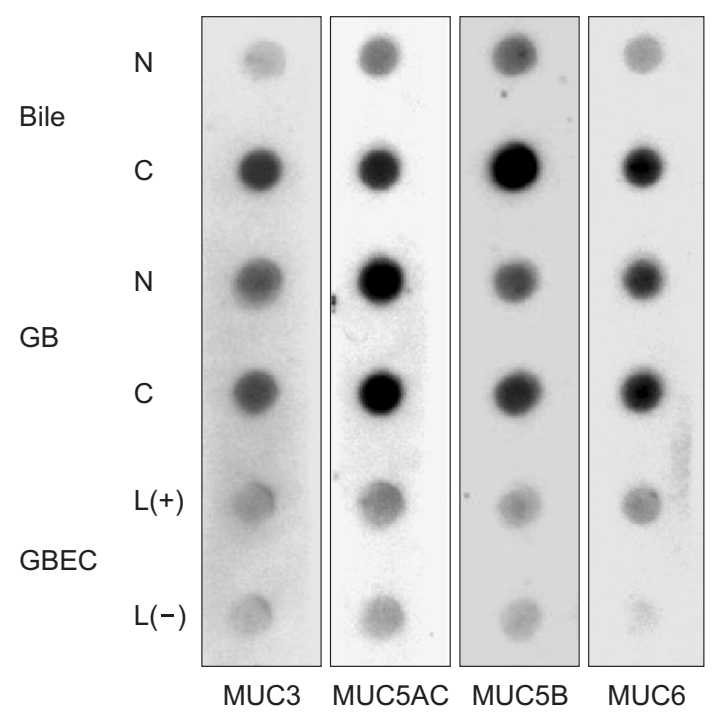

Fig. 4. MUC protein expression in bile, gallbladder (GB) tissue and canine gallbladder epithelial cells (GBECs) as shown by dot/slot blotting. Bile and gallbladder tissues from patients with cholecystitis and cholesterol stones commonly showed increased expression of MUC3 and MUC5B. Slightly increased levels of MUC3, MUC5B, and MUC6 were observed following treatment of canine GBECs with lipopolysaccharide.
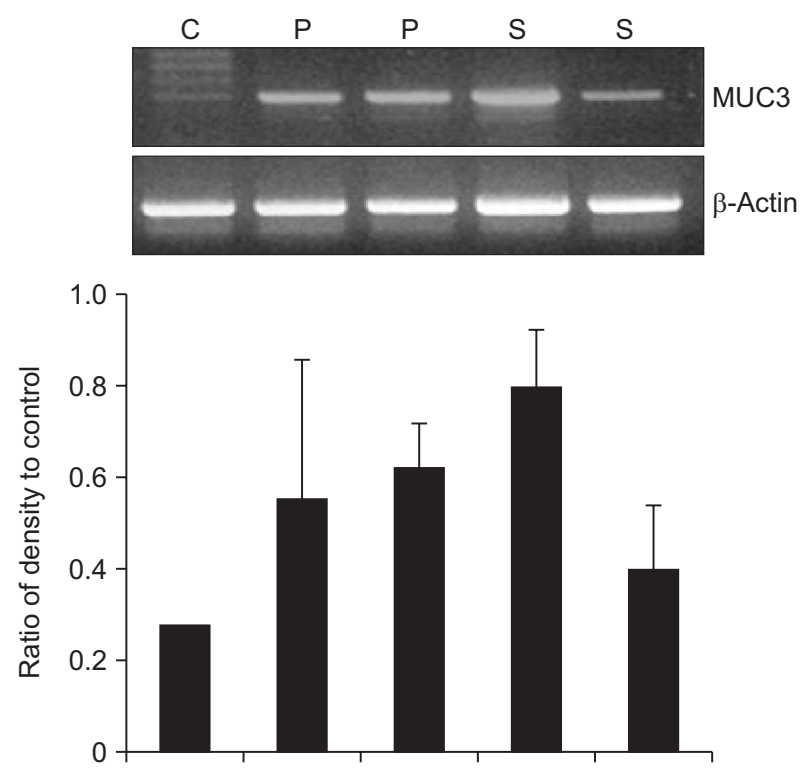

\section{Expression of MUC genes in gallbladder epithelium in gallstone diseases}

RT-PCR was used to compare MUC3 and MUC5B gene expression among patients with cholecystitis secondary to cholesterol stones and those with cholesterol polyps. Both groups had higher MUC3 and MUC5B gene expression than normal controls (Fig. 5), with highest expression seen for MUC5B.

\section{Expression of MUC genes in DGBECs with LPS treatment}

To evaluate changes in MUC gene expression induced by inflammation, $100 \mu \mathrm{g} / \mathrm{mL}$ or $200 \mu \mathrm{g} / \mathrm{mL}$ LPS was added for 4 , 8 , or 24 hours in cholesterol-free conditions. In all conditions, MUC3 and MUC5B mRNA was significantly overexpressed compared to normal controls. Expression of MUC5B mRNA was particularly affected, with increased expression at 4 to 8 hours of LPS treatment followed by a decreasing trend by 24 hours (Fig. 6).

\section{DISCUSSION}

MUC3, MUC5AC, MUC5B, and MUC6 were expressed in human gallbladder epithelial cells, and MUC3 and MUC5B had the highest expression of these mucin genes in cholesterol associated gallbladder diseases. MUC3 and MUC5B showed a markedly different expression pattern in cholesterol associated gallbladder disease compared to normal tissue, which could indicate their importance in gallbladder disease pathogenesis.

For a cholesterol crystal to develop from gallbladder bile, at least three steps must occur: cholesterol supersaturation of gallbladder bile, rapid progression of nucleation, and long-term
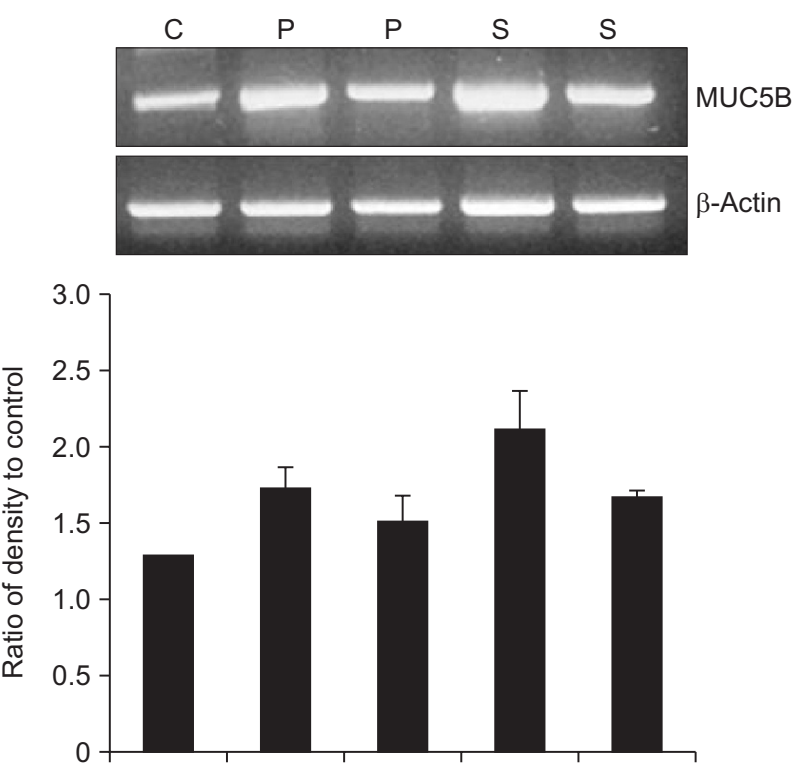

Fig. 5. MUC gene expression in gallbladder tissues. Both MUC3 and MUC5B mRNA were upregulated in the cholecystitis with cholesterol stone (S) and cholesterol polyp (P) groups compared with the control group (C) $(\mathrm{p}<0.05)$.

Lane 1, normal control; Lanes 2 and 3, cholesterol polyp; Lanes 4 and 5, cholecystitis with cholesterol stone. 


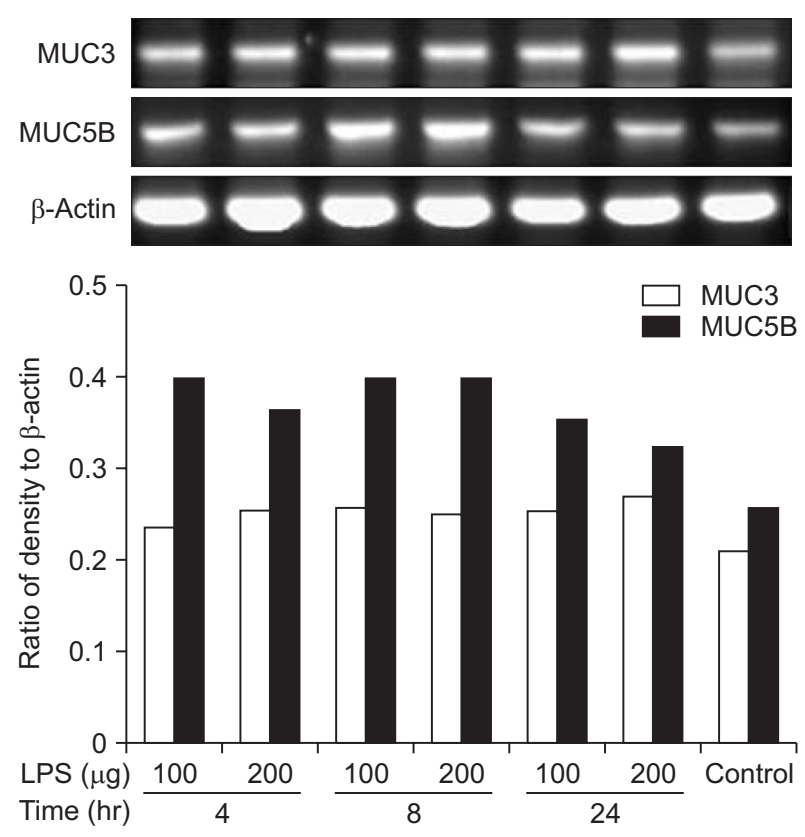

Fig. 6. MUC gene expression in dog gallbladder epithelial cells (DGBECs). Lipopolysaccharide-treated canine GBECs showed overexpression of both MUC3 and MUC5B mRNA compared to controls $(\mathrm{p}<0.05)$.

stasis due to gallbladder hypomotility. Cholesterol supersaturation is essential for, but does not always induce, gallstone formation. A balance between prenucleating and antinucleating factors in the bile allows for supersaturation without nucleation. Nucleation occurs when the balance between the nucleating and antinucleating factors is disrupted.

Upregulation of these MUC genes could lead to the observed increased gallbladder mucin concentrations. Mucin may increase bile viscosity leading to the formation of a gel matrix that can entrap cholesterol crystals in the gallbladder. ${ }^{31}$ Mucin may also enhance cholesterol crystallization by offering low-affinity binding sites for cholesterol. ${ }^{32-34}$ The present study revealed a marked increase in MUC3 and MUC5B in the gallbladder epithelium of patients with cholesterol stones with cholesterolosis or cholecystitis. The findings suggest that MUCs are involved in diseases caused by cholesterol supersaturation, consistent with the findings of other studies.

Lee and $\mathrm{Liu}^{21}$ analyzed differences in apomucin gene expression in gallbladder epithelium with pigment stones and normal gallbladder epithelium and showed that MUC1, MUC3, MUC5B, and MUC6 were more highly expressed in the gallbladder epithelium of patients with pigment stones. Expression was significantly reduced by 33.3\% for MUC1, 83.3\% for MUC3, 83.3\% for MUC5B, and 66.7\% for MUC6 in normal gallbladder epithelium compared to diseased tissue. In addition, expression was higher in the pigment stone group than in the normal control group. MUC2 and MUC4 were not expressed in normal gallbladder but did show expression rates of $20 \%$ and $60 \%$, respectively, in the pigment stone group. Changes in the mucin environment are presumed to be involved in formation of pigment stones. Kim et al. ${ }^{35}$ compared MUC3, MUC5AC, and MUC6 expression in the gallbladder epithelium associated with both cholesterol and pigment gallstones and found no significant differences in MUC gene expression. Vilkin et al. ${ }^{30}$ demonstrated that MUC3, MUC5AC, MUC5B and MUC6 are expressed in the gallbladder epithelium mainly with pigment stone and MUC5AC and MUC5B are secreted into bile. Recent study demonstrated that several mucin proteins were overexpressed in the gallbladder with pigment stones and inflamed gallbladder. ${ }^{30}$ However, expression of various MUC in gallbladder with cholesterol gallstone and cholesterol stone-related disease still remains largely unknown.

The increase in MUC protein expression associated with infection was examined in cell culture experiments. LPS from E. coli increases MUC protein secretion, principally MUC2 and MUC5A, in mouse and dog gallbladder epithelium. ${ }^{1,4}$ We found that MUC3 and MUC5B expression increased in the bile and gallbladder epithelium of cholecystitis patients, presumed to be accompanied by infection. A similar result was observed in DGBECs with LPS-induced inflammation. We interpreted these results as indicating that infection or inflammatory conditions contribute to MUC protein expression, suggesting involvement in gallstone formation. In addition, we found overexpression of MUC3 and MUC5B in patients with cholesterol stones, regardless of the presence of cholesterolosis or cholecystitis. This result suggests that MUC secretion increases in infection or cholesterol supersaturation conditions and contributes to gallstone formation.

Recent study showed that MUC5AC was overexpressed in gallbladder with pigment stone than one with cholesterol stone. ${ }^{30}$ MUC5AC was also overexpressed in gallbladder with cholesterol stone and cholesterol polyp as well in present study but it was weaker than the expression of both MUC3 and MUC5B. Therefore, we performed RT-PCR in gallbladder tissue and DGBECs for only MUC3 and MUC5B genes. It is still unclear whether expression of various MUC is different between gallstone types regarding conflicting results of previous studies. ${ }^{21,30,35}$ Further study with large sample size to compare the expression of MUC between various stone types would be needed in the future.

Only $10 \%$ to $15 \%$ of bile samples were positive for bacterial cultures, and no bacteria were isolated from surgically-removed cholesterol stones. To date, the demonstrated relationship between cholesterol gallstones and bacterial infection has been weak. ${ }^{36}$ However, 16S rRNA sequence analysis demonstrated that, although no bacterial DNA is present in pure cholesterol stones with cholesterol content greater than 90\%, bacterial DNA is found in $70 \%$ to $90 \%$ of samples of mixed stones. E. coli were cultured from most of these mixed stone samples, suggesting involvement of bacterial infection in the formation of cholesterol gallstones. ${ }^{7}$ Clinically, the incidence of pure cholesterol stones is low, and mixed stones are the predominant cause of most gallstone cases. ${ }^{7,37}$ Experiments using tissue from clinical 
patients for evaluating how an infection-induced inflammatory condition affects MUC gene and protein expression formation are inherently limited. For this reason, we used cultured DGBECs treated with LPS to measure MUC3 and MUC5B gene expression using RT-PCR. A significant increase in the expression of MUC3 and MUC5B mRNA was observed, suggesting that infectioninduced inflammation is essential for MUC expression.

Present study showed a unique pattern of various MUC expression regarding conflicting results of previous studies. ${ }^{21,30,35}$ All gallbladder specimens of present study obtained from cholesterol associated gallbladder diseases. The expression pattern of various MUCs may be different between gallstone types, however it still remains unclear. Additionally, the mechanism of overexpression- of various MUCs might be different in gallstone disease. Previous study suggested that MUC5AC mRNA and protein production was significantly increased in gallbladder with cholesterol stones by EGF-R ligands (either EGF or transforming growth factor- $\alpha$ ) in the presence of TNF- $\alpha$, whereas expression of the other gallbladder mucins MUC1, MUC3, and MUC5B was unchanged. ${ }^{38}$ The pattern of expression of mucin core proteins in gallbladder epithelium with cholecystitis also may be altered with increasing degrees of inflammation. Ho et al. ${ }^{25}$ showed that MUC5AC was most significantly decreased in gallbladder specimens with acute inflammation compared with MUC5B. The relative functional roles of each of these individual mucin glycoproteins in mucosal cytoprotection and gallstone formation remain to be determined.

The expression of MUC3 and MUC5B increased slightly in patients with cholesterol polyps and gallbladder cancer; expression of other MUCS was negligible. However, since the study population was small with no stage categorization, additional studies focusing on MUC as a prognostic factor in neoplastic diseases of the gallbladder are needed.

In conclusion, MUC3, MUC5AC, MUC5B, and MUC6 were expressed in the normal gallbladder epithelium, with MUC3 and MUC5B being the most highly expressed. Diseases associated with cholesterol supersaturation, such as cholesterol stones and cholesterolosis, and infection induced by inflammation within the gallbladder were associated with overexpression of MUC3 and MUC5B. These events were presumed to be closely related to gallstone formation. In future studies, the relationship between cytokines and inflammation related to MUC expression should be explored, in addition to the mechanism that controls MUC expression.

\section{CONFLICTS OF INTEREST}

No potential conflict of interest relevant to this article was reported.

\section{ACKNOWLEDGEMENTS}

This work was supported by the research fund of Hanyang University (HY-2013-MC).

\section{REFERENCES}

1. Zen Y, Harada K, Sasaki M, et al. Lipopolysaccharide induces overexpression of MUC2 and MUC5AC in cultured biliary epithelial cells: possible key phenomenon of hepatolithiasis. Am J Pathol 2002;161:1475-1484.

2. Apstein MD, Carey MC. Pathogenesis of cholesterol gallstones: a parsimonious hypothesis. Eur J Clin Invest 1996;26:343-352.

3. Berr F, Pratschke E, Fischer S, Paumgartner G. Disorders of bile acid metabolism in cholesterol gallstone disease. J Clin Invest 1992;90:859-868.

4. Choi J, Klinkspoor JH, Yoshida T, Lee SP. Lipopolysaccharide from Escherichia coli stimulates mucin secretion by cultured dog gallbladder epithelial cells. Hepatology 1999;29:1352-1357.

5. Sheen PC, Lee KT, Liu YE. Mucin content in gallbladders with brown pigment stones or combination stones with a brown periphery. Digestion 1998;59:660-664.

6. Yamasaki T, Nakayama F, Tamura S, Endo M. Characterization of mucin in the hepatic bile of patients with intrahepatic pigment stones. J Gastroenterol Hepatol 1992;7:36-41.

7. Lee DK, Tarr PI, Haigh WG, Lee SP. Bacterial DNA in mixed cholesterol gallstones. Am J Gastroenterol 1999;94:3502-3506.

8. Enss ML, Müller H, Schmidt-Wittig U, Kownatzki R, Coenen M, Hedrich HJ. Effects of perorally applied endotoxin on colonic mucins of germfree rats. Scand J Gastroenterol 1996;31:868-874.

9. Steiger D, Hotchkiss J, Bajaj L, Harkema J, Basbaum C. Concurrent increases in the storage and release of mucin-like molecules by rat airway epithelial cells in response to bacterial endotoxin. Am J Respir Cell Mol Biol 1995;12:307-314.

10. Sasaki M, Nakanuma Y, Kim YS. Expression of apomucins in the intrahepatic biliary tree in hepatolithiasis differs from that in normal liver and extrahepatic biliary obstruction. Hepatology 1998;27:54-61.

11. Van Klinken BJ, Dekker J, Büller HA, Einerhand AW. Mucin gene structure and expression: protection vs. adhesion. Am J Physiol 1995;269(5 Pt 1):G613-G627.

12. Vandenhaute B, Buisine MP, Debailleul V, et al. Mucin gene expression in biliary epithelial cells. J Hepatol 1997;27:1057-1066.

13. Keicho N, Hijikata M. Genetic predisposition to diffuse panbronchiolitis. Respirology 2011;16:581-588.

14. Bobek LA, Tsai H, Biesbrock AR, Levine MJ. Molecular cloning, sequence, and specificity of expression of the gene encoding the low molecular weight human salivary mucin (MUC7). J Biol Chem 1993;268:20563-20569.

15. Desseyn JL, Guyonnet-Dupérat V, Porchet N, Aubert JP, Laine A. Human mucin gene MUC5B, the 10.7-kb large central exon encodes various alternate subdomains resulting in a super-repeat. Structural 
evidence for a 11p15.5 gene family. J Biol Chem 1997;272:31683178.

16. Dufosse J, Porchet N, Audie JP, et al. Degenerate 87-base-pair tandem repeats create hydrophilic/hydrophobic alternating domains in human mucin peptides mapped to $11 \mathrm{p} 15$. Biochem J 1993;293(Pt 2):329-337.

17. Freston JW, Bouchier IA, Newman J. Biliary mucous substances in dihydrocholesterol-induced cholelithiasis. Gastroenterology 1969;57:670-678.

18. Gallinger S, Taylor RD, Harvey PR, Petrunka CN, Strasberg SM. Effect of mucous glycoprotein on nucleation time of human bile. Gastroenterology 1985;89:648-658.

19. Gendler SJ, Lancaster CA, Taylor-Papadimitriou J, et al. Molecular cloning and expression of human tumor-associated polymorphic epithelial mucin. J Biol Chem 1990;265:15286-15293.

20. Gum JR, Hicks JW, Swallow DM, et al. Molecular cloning of cDNAs derived from a novel human intestinal mucin gene. Biochem Biophys Res Commun 1990;171:407-415.

21. Lee KT, Liu TS. Mucin gene expression in gallbladder epithelium with black pigment stone ascertained by in situ hybridization. Kaohsiung J Med Sci 2001;17:517-523.

22. Smith BF, LaMont JT. Identification of gallbladder mucin-bilirubin complex in human cholesterol gallstone matrix: effects of reducing agents on in vitro dissolution of matrix and intact gallstones. J Clin Invest 1985;76:439-445.

23. Carrato C, Balague C, de Bolos C, et al. Differential apomucin expression in normal and neoplastic human gastrointestinal tissues. Gastroenterology 1994;107:160-172.

24. De Bolós C, Garrido M, Real FX. MUC6 apomucin shows a distinct normal tissue distribution that correlates with Lewis antigen expression in the human stomach. Gastroenterology 1995;109:723734.

25. Ho SB, Roberton AM, Shekels LL, Lyftogt CT, Niehans GA, Toribara NW. Expression cloning of gastric mucin complementary DNA and localization of mucin gene expression. Gastroenterology 1995;109:735-747.

26. Keates AC, Nunes DP, Afdhal NH, Troxler RF, Offner GD. Molecular cloning of a major human gall bladder mucin: complete C- terminal sequence and genomic organization of MUC5B. Biochem J 1997;324(Pt 1):295-303.

27. Oda D, Lee SP, Hayashi A. Long-term culture and partial characterization of dog gallbladder epithelial cells. Lab Invest 1991;64:682692

28. van Klinken BJ, Oussoren E, Weenink JJ, et al. The human intestinal cell lines Caco-2 and LS174T as models to study cell-type specific mucin expression. Glycoconj J 1996;13:757-768.

29. Chuang SC, Hsi E, Lee KT. Mucin genes in gallstone disease. Clin Chim Acta 2012;413:1466-1471.

30. Vilkin A, Nudelman I, Morgenstern S, et al. Gallbladder inflammation is associated with increase in mucin expression and pigmented stone formation. Dig Dis Sci 2007;52:1613-1620.

31. Smith BF. Gallbladder mucin as a pronucleating agent for cholesterol monohydrate crystals in bile. Hepatology 1990;12(3 Pt 2):183S-186S.

32. Venneman NG, van Erpecum KJ. Pathogenesis of gallstones. Gastroenterol Clin North Am 2010;39:171-183.

33. Afdhal NH, Smith BF. Cholesterol crystal nucleation: a decadelong search for the missing link in gallstone pathogenesis. Hepatology 1990;11:699-702.

34. Yang HM, Wu J, Li JY, Gu L, Zhou MF. Role of nucleation of bile liquid crystal in gallstone formation. World J Gastroenterol 2003; 9:1791-1794.

35. Kim HJ, Kim JS, Kim KO, et al. Expression of MUC3, MUC5AC, MUC6 and epidermal growth factor receptor in gallbladder epithelium according to gallstone composition. Korean J Gastroenterol 2003;42:330-336

36. Haigh WG, Lee SP. Identification of oxysterols in human bile and pigment gallstones. Gastroenterology 2001;121:118-123.

37. Swidsinski A, Ludwig W, Pahlig H, Priem F. Molecular genetic evidence of bacterial colonization of cholesterol gallstones. Gastroenterology 1995;108:860-864.

38. Finzi L, Barbu V, Burgel PR, et al. MUC5AC, a gel-forming mucin accumulating in gallstone disease, is overproduced via an epidermal growth factor receptor pathway in the human gallbladder. Am J Pathol 2006;169:2031-2041. 